\title{
Tsafon
}

Revue d'études juives du Nord

$72 \mid 2016$

Juifs, Israéliens, dans la littérature française et israélienne

\section{Joëlle Allouche-Benayoun et Geneviève Dermenjian (sous la direction de), Les Juifs d'Algérie, une histoire de rupture}

Danielle Delmaire

\section{Q OpenEdition}

\section{Journals}

Édition électronique

URL : https://journals.openedition.org/tsafon/487

DOI : $10.4000 /$ tsafon.487

ISSN : 2609-6420

\section{Éditeur}

Association Jean-Marie Delmaire

Édition imprimée

Date de publication : 1 décembre 2016

Pagination : 178-180

ISSN : $1149-6630$

\section{Référence électronique}

Danielle Delmaire, « Joëlle Allouche-Benayoun et Geneviève Dermenjian (sous la direction de), Les Juifs d'Algérie, une histoire de rupture», Tsafon [En ligne], 72 | 2016, mis en ligne le 31 mai 2018, consulté le 24 juin 2021. URL : http://journals.openedition.org/tsafon/487 ; DOl : https://doi.org/10.4000/tsafon. 487

Ce document a été généré automatiquement le 24 juin 2021.

Tsafon. Revues d'études juives du Nord 


\title{
Joëlle Allouche-Benayoun et Geneviève Dermenjian (sous la direction de), Les Juifs d'Algérie, une histoire de rupture
}

\author{
Danielle Delmaire
}

\section{RÉFÉRENCE}

Joëlle Allouche-Benayoun et Geneviève Dermenjian (sous la direction de), Les Juifs d'Algérie, une histoire de rupture, Aix-en-Provence, Presses universitaires de Provence, coll. Le temps de l'histoire, 2015, 314 p., $25 €$.

1 L'ouvrage rassemble, sous la direction de Joëlle Allouche-Benayoun, chercheure CNRS en psychologie sociale, et Geneviève Dermenjian, historienne des juifs d'Algérie et de l'antisémitisme, les interventions prononcées lors d'un colloque qui se déroula le 18 novembre 2012, sur le thème: «Juifs d'Algérie, du dhimmi au citoyen français » ainsi que quelques contributions sur le même thème, écrites en dehors de ce colloque.

2 L'histoire des juifs d'Algérie, depuis l'arrivée des Français en 1830 jusqu'à l'indépendance de l'Algérie en 1962, et même après, est bien «une histoire de rupture ». Du statut de dhimmi inférieur à ses voisins musulmans, le juif d'Algérie est hissé à la citoyenneté française grâce au décret Crémieux (1870), puis il subit les violences antisémites tant des Arabes que des Européens avant d'être encore discriminé par la législation du gouvernement de Vichy. Rupture avec le monde arabe, rupture avec la France vichyste et enfin rupture avec le pays: ses villes, ses campagnes, ses paysages etc. Les dates fortes qui scandent les communications sont : 1830, l'arrivée de l'armée française, 1870, le décret Crémieux qui émancipe les juifs sans émanciper les autres «indigènes ", 1934, les émeutes antisémites de Constantine, 1940-1942, la persécution raciale du régime de Vichy qui les atteint également. 
3 Dans son introduction, Joëlle Allouche-Benayoun fait remonter la présence juive en Afrique du Nord à l'époque de Carthage et aux conversions d'une partie de la population berbère, avant donc l'expansion arabo-musulmane qui instaure l'humiliante dhimmitude. Le XIXe siècle apporte donc, aux juifs d'Algérie, d'abord la modernité puis l'émancipation. Humilié avant l'arrivée des Français, voilà le juif supérieur au musulman, à l'indigène grâce au décret Crémieux. Denis Charbit élabore une historiographie complète de ce fameux décret, n'oubliant pas de souligner qu'en un premier temps, les signataires de ce décret, qui donnait à la France environ 40000 citoyens en plus, voyaient une compensation à la perte du même nombre quasiment de juifs alsaciens et lorrains suite à la disparition des provinces orientales de la France.

4 Suit un ensemble de contributions qui analysent la mission civilisatrice de la France auprès des juifs d'Algérie. Valérie Assan, auteure d'une thèse sur les consistoires israélites d'Algérie du $\mathrm{xIX}^{\mathrm{e}}$ siècle, note qu'avec la francisation, l'organisation consistoriale est implantée en Algérie et les rabbins doivent être soumis à une formation française. Ce qui provoque quelques réactions hostiles de la part de rabbins « indigènes » qui voient leur autorité contestée par des rabbins métropolitains qui les regardent avec mépris. La mission civilisatrice de la France ne s'impose pas aisément. Philippe Danan et Danièle Iancu-Agou, historienne originaire d'Algérie, offrent une histoire de deux villes: Constantine pour le premier et l'oasis Bou-Saâda pour la seconde. P. Danan mène une enquête pour démonter la rumeur d'une hostilité des juifs qui auraient tiré sur les Français en 1830. En réalité, ils s'accommodent rapidement de la législation française. Quant à $\mathrm{D}$. Iancu-Agou, elle décrit avec précision et un peu de tendresse les petits métiers des juifs de cette oasis, "cité française " qui séduisit les peintres orientalistes. Autre conséquence de la présence française, la position intermédiaire des interprètes juifs auprès de l'armée française de 1830 à 1870 qui pratiquent l'arabe et la langue des conquérants. Une «facette méconnue » de l'histoire des juifs d'Algérie que dévoile Sabrina Dufourmont.

Et malgré cette "mission civilisatrice ", l'antisémitisme est " une constante » dans l'histoire de l'Algérie. Geneviève Dermejian situe très bien les juifs d'Algérie «entre deux hostilités " celle des musulmans, qui imposèrent la dhimmitude mais qui ont conservé leur mépris du juif après l'émancipation de ce dernier, celle des Français qui apportèrent avec eux l'antisémitisme qui sévit en France notamment lors de l'affaire Dreyfus. Durant cette dernière décennie du $\mathrm{XIX}^{\mathrm{e}}$ siècle, des antisémites notoires occupent les mairies de Constantine (Morinaud), d'Oran (Gobert) et d'Alger (Max Régis l'ami de Drumont, député d'Alger). Et la presse n'est pas en reste. La Libre parole de Drumont s'implante en Algérie, sous le titre La Libre Parole Nord africaine, où elle obtient un lectorat attentif chez les Européens. Mais en 1934, ce sont principalement des Arabes qui dévastent les maisons juives. Constant encore est cet antisémitisme durant la Seconde Guerre mondiale. La législation raciste de Vichy sévit en Algérie à commencer par l'abrogation, dès 1940, du décret Crémieux qui exclut les juifs de la citoyenneté française, puis suit l'aryanisation des entreprises juives. L'Algérie connut également des camps d'internement aux conditions de vie très dures selon l'article de Jacob Oliel. Des juifs y furent martyrisés gratuitement parce que juifs. Quant aux juifs d'Algérie qui s'étaient installés à Marseille avant la guerre, les arrestations et la déportation ne les ont pas épargnés expliquent Renée Dray-Bensoussan.

6 Cette constante antisémite est réelle pour Jean-Pierre Lledo dont le «regard de cinéaste » témoigne de « la judéophobie musulmane en Algérie avant, pendant et après 
la période française ». Les propos sont édifiants et sans ambiguïté de la part de l'auteur qui a cru pouvoir rester dans l'Algérie algérienne après l'indépendance mais qui a dû fuir l'Algérie devenue musulmane exclusivement. Il dénonce avec véhémence l'antisémitisme de l'actuelle Algérie, les citations qu'il reproduit en pp. 192-193 sont convaincantes.

7 Reste donc la mémoire de cette présence juive, millénaire, en Algérie. Une « mémoire collective des Juifs d'Algérie» qu'Ethan Katz situe «entre émancipation et antijudaïsme » car dans ces deux mots réside toute l'ambiguïté de l'histoire des juifs d'Algérie. L'émancipation les a fait entrer dans la modernité et la francité mais l'antijudaïsme les a exclu de l'arabité. L'article revient sur la férocité des soulèvements de Constantine en 1934 en soulignant la violence et la vulnérabilité dont étaient victimes les juifs. Annie Stora Lamarre, historienne originaire de Constantine, et le grand rabbin René-Samuel Sirat, originaire également d'Algérie, livrent leur témoignage sur la vie au féminin en Algérie puis en France, pour la première, et l'attachement des rabbins "indigènes » aux valeurs du judaïsme parfois mises à mal par les "Européens ", pour le second. Quant au cimetière de Saint-Eugène, où furent enterrés de célèbres érudits juifs, il demeure un triste «lieu de mémoire des Juifs d'Alger " car il est défiguré par l'abandon et la profanation des tombes. Les photos de Jean-Paul Durand, datant de 2007-2010, en témoignent. Les informations d'un site internet pallient les effacements des inscriptions sur les pierres tombales. La mémoire est encore présente dans la "poétique d'une reconstruction identitaire » que Danielle Dahan-Feucht restitue grâce à deux textes : Errances de Pierre Bentolila et Traversées de Jacqueline Sudaka-Bénazéraf.

«Après 1962 » où se trouvent les juifs d'Algérie ? À la différence des juifs du Maroc et de Tunisie qui majoritairement se sont dirigés vers Israël lorsqu'il leur a fallu quitter leur pays, les juifs d'Algérie ont donné la préférence à la France, la mère patrie puisqu'ils en étaient citoyens. Toutefois, actuellement, parmi les juifs de France qui font leur alyah, ceux qui sont originaires d'Algérie constituent la majorité. Illustrant son article, Éliézer Ben-Rafael donne à regarder les vitrines de "la francophonie au cœur de Natanya ». Et l'ouvrage se clôt sur le récit de Benjamin Stora, l'historien de l'Algérie, né à Constantine, qui décrit les trois chocs subis par ses parents : la crise de 1930 qui atteint rudement sa famille, la perte de la citoyenneté en 1940 et enfin l'exil en 1962.

9 L'opus s'enrichit d'une abondante bibliographie mais qui, malheureusement, ne fait pas le tri entre les ouvrages anciens du XIX ${ }^{e}$ siècle, qui devraient être considérés comme des sources, et des études récentes. Quant aux sources, les intervenants ont puisé dans de nombreux fonds : l'Alliance israélite universelle, le consistoire de France, les archives de la préfecture de police de Paris, le centre des archives sionistes à Jérusalem et de nombreux sites internet. Enfin un glossaire arabe et hébreu aide le lecteur à comprendre certains mots. 